\title{
Three Pseudomonas aeruginosa strains with different protease profiles
}

\author{
Mariola Andrejko ${ }^{凶}$, Agnieszka Zdybicka-Barabas', Monika Janczarek² \\ and Małgorzata Cytryńska' \\ 1Department of Immunobiology and 2Department of Genetics and Microbiology, Maria Curie-Sklodowska University, Lublin, Poland
}

\begin{abstract}
The proteolytic activity of three Pseudomonas aeruginosa strains, ATCC 27853 - a reference strain, and two clinical isolates was tested. The activity was examined after culturing the bacteria in two different growth media: the minimal M9 medium and rich Luria-Bertani broth (LB). Based on zymograms and protease activity specific assays, it was concluded that the reference strain produced three proteolytic enzymes in the LB medium: protease IV, elastase B and elastase A, while alkaline protease was only produced in the M9 medium. The clinical isolates of $P$. aeruginosa produced elastase B and alkaline protease when grown in the LB medium and the minimal M9 medium, respectively. PCR analysis confirmed the presence of both the Ias $B$ gene encoding elastase $B$ and aprA coding for alkaline protease in the genomes of the three $P$. aeruginosa strains analyzed. The expression of these genes coding for two important $P$. aeruginosa virulence factors was dependent on the growth conditions in all the strains studied. The contribution of the extracellular proteinases to the virulence of $P$. aeruginosa strains used in this study was investigated using an insect model, the greater wax moth Galleria mellonella.
\end{abstract}

Key words: Pseudomonas aeruginosa, extracellular proteases, elastase B, alkaline protease, las B, aprA, virulence

Received: 05 October, 2012; revised: 18 December, 2012; accepted: 27 February, 2013; available on-line: 19 March, 2013

\section{INTRODUCTION}

Pseudomonas aeruginosa is a common environmental Gram-negative opportunistic pathogen of diverse hosts including mammals, insects, nematodes and plants. The bacterium has been implicated in various human diseases, e.g. keratitis, pneumonias and burn wound infections (Dart \& Seal, 1988; Jarvis \& Martone, 1992; Pruitt et al., 1998). Different strains of $P$. aeruginosa secrete several extracellular proteolytic enzymes that have been implicated as virulence factors. They include protease IV, alkaline protease (aeruginolysin), and two elastases, LasA (staphylolysin) and LasB (pseudolysin) (Caballero et al., 2001). The proteases promote development of the bacteria within the infected host and interfere with the host immune system (Jarosz, 1995; Jin et al., 1996; Miyoshi et al., 2002; Hung et al., 2005; Hoge et al., 2010).

Elastase A (LasA) is a metalloproteinase with a molecular mass of approximately $22 \mathrm{kDa}$ belonging to the $\beta$-lytic family of $\mathrm{Zn}$-metalloendopeptidases. LasA possesses a high staphylolytic activity that lyses Staphylococcus aureus cells by cleaving the pentaglycine bridges with- in the peptidoglycan and may also enhance elastolysis by cleaving Gly-Gly peptide bonds abundant in elastin (Peters \& Galloway, 1990; Toder et al., 1991; Kessler et al., 1993, 1997). This protease has been suggested as a secreted $P$. aeruginosa virulence factor in animal models of corneal and lung infections. LasA is responsible for shedding of the host cell surface proteoglycan syndecan-1 (Preston et al., 1997; Park et al., 2000).

Elastase $\mathrm{B}$ is a $33-\mathrm{kDa}$ endopeptidase belonging to the thermolysin family (M4 peptidase); it hydrolyses the peptide bond at the amino side of the $\mathrm{P} 1$ ' amino acid residue, usually a hydrophobic one (Morihara et al., 1965; Matthews, 1988; Thayer et al., 1991; Miyoshi \& Shinoda, 2000). Elastase B is involved in pathogenesis by degradation of human immunologically competent molecules. It is proven that LasB destroys complement components (Schultz \& Miller, 1974), cytokines (Parmely et al., 1990), immunoglobulins IgA and IgG (Buret \& Cripps, 1993; Maeda \& Yamamoto, 1996), human airway lysozyme (Jacquot et al., 1985), proteinase-activated receptors (Dulon et al., 2005) and surfactant proteins A and D (Mariencheck et al., 2003).

Another protease involved in the virulence of $P$. aeruginosa is a metalloprotease, alkaline protease, which belongs to the serralysin family (aeruginolysin, APR) (Morihara et al., 1973; Okuda et al., 1990). Structural comparison has revealed that APR is homologous to the $50-\mathrm{kDa}$ metalloproteinases secreted by Serratia marcescens and Erwinia chrysanthemi (Maeda \& Morihara, 1995). Alkaline protease degrades casein and gelatin, and migrates in zymography gels as a protein of approximately $56 \mathrm{kDa}$ (Caballero et al., 2001). APR is implicated in hydrolysis of many biologically important proteins including the $\alpha_{1}$-proteinase inhibitor (Morihara et al., 1979), cytokines (Parmely et al., 1990), complement factors (Hong \& Ghebrehiwet, 1992), laminin (Heck et al., 1986), matrix metalloproteinases (Twining et al., 1993), human $\gamma$-interferon and tumor necrosis factor- $\alpha$ (Horvat \& Parmely, 1988; Parmely et al., 1990).

In contrast to the three metalloproteases mentioned above, protease IV is a serine endoprotease with a molecular mass of $26 \mathrm{kDa}$. The enzyme specifically cleaves substrates on the carboxyl side of lysine residues. Protease IV is capable of degrading a number of biologically important proteins of the mammalian immune system including immunoglobulins, elements of the complement system, fibrinogen and plasminogen (Engel et al., 1998).

e-mail: mariola.andrejko@poczta.umcs.lublin.pl

Abbreviations: APR, alkaline protease; EDTA, ethylenediaminetetraacetic acid; LB, Luria-Bertani broth; PAGE, polyacrylamide gel electrophoresis; PCR, polymerase chain reaction; TLCK, tosyl-L-lysine chloromethylketone 
The purpose of the present study was to characterize the proteolytic profile of two clinical isolates of $P$. aeruginosa (PA C124/9 and PA 02/18) and to determine the effects of culture conditions on the production of extracellular proteases by the strains. Our preliminary experiments indicated a relatively low level of total proteinase activity in culture supernatants of these strains. In parallel, as a reference strain, $P$. aeruginosa strain ATCC 27853 from culture collections was investigated. The level of total proteinases as well as specific activities of elastase A, elastase B, protease IV and alkaline protease produced by the tested strains under defined culture conditions were quantitatively examined. In addition, identification of las $B$ and $\operatorname{apr} A$ genes, encoding elastase $B$ and alkaline protease, respectively, in the genomes of the strains was performed. To evaluate the contribution of the detected proteinases to the virulence of the clinical isolates, an insect model, the greater wax moth Galleria mellonella, was used. Larvae of this lepidopteran insect have been exploited as a model in numerous studies on virulence factors of different pathogens, including bacteria such as P. aeruginosa (Dunphy et al., 1986; Miyata et al., 2003), Francisella tularensis (Aperis et al., 2007), Staphylococcus aureus (Garcia-Lara et al., 2005), Enterococcus fecalis (Park et al., 2007), Burkholderia cepacia (Seed \& Dennis, 2008), Listeria monocytogenes (Mukherjee et al., 2010) and Legionella pneumophila (Harding et al., 2012). Considerable analogies were reported between the virulence of $P$. aeruginosa in mice and G. mellonella larvae (Jander et al., 2000).

\section{MATERIALS AND METHODS}

Bacterial strains. A pyocyanin-producing Pseudomonas aeruginosa strain ATCC 27853, i.e. an isolate of moderate virulence to the $7^{\text {th }}$ instar larvae of the greater wax moth Galleria mellonella ( $\mathrm{LD}_{50}=17$ cells), and two clinical strains, PA C124/9 (PA9) and PA 02/18 (PA18) provided by Prof. E. A. Trafny (Department of Microbiology and Epidemiology, Military Institute of Hygiene and Epidemiology in Warsaw, Poland) were used in the study. The bacteria were grown overnight at $37^{\circ} \mathrm{C}$ in $\mathrm{Lu}-$ ria-Bertani broth (LB broth, Sigma) or M9 minimal medium supplemented with monosodium glutamate $(0.13$ $\mathrm{M})$, glycerol $(0.1 \mathrm{M})$ and $\mathrm{CaCl}_{2}(0.01 \mathrm{M})$.

Preparation of culture supernatants. In order to obtain culture supernatants, $5 \mathrm{ml}$ of culture medium (LB or M9) in a tube was inoculated with a loop of bacterial cells and the bacteria were grown overnight at $37^{\circ} \mathrm{C}$ under constant rotation at $120 \mathrm{rpm}$. Then, supernatants were obtained by centrifugation at $8000 \times \mathrm{g}$ for $10 \mathrm{~min}$ at $4^{\circ} \mathrm{C}$. The supernatant samples were stored at $-20^{\circ} \mathrm{C}$. The respective supernatants were determined: ATCC LB, PA9 LB and PA18 LB (strains ATCC, PA9 and PA18 grown in LB medium) and ATCC M9, PA9 M9 and PA18 M9 (strains ATCC, PA9 and PA18 grown in minimal medium M9).

Determination of total protease activity. Total protease activity of the culture supernatants was estimated using azocasein as a substrate with a modified method described by Kessler et al. (1982). The assay mixture contained $0.25 \mathrm{ml}$ of azocasein (Fluka) ( $5 \mathrm{mg} / \mathrm{ml}$ ) dissolved in water and $0.25 \mathrm{ml}$ of the culture supernatant. After incubation at $37^{\circ} \mathrm{C}$ for $60 \mathrm{~min}$, the reaction was stopped by addition of trichloroacetic acid $(10 \%, 0.5 \mathrm{ml})$. Precipitated azocasein was then pelleted at $20000 \times g$ for $10 \mathrm{~min}$. The supernatant obtained $(0.75 \mathrm{ml})$ was mixed with $\mathrm{NaOH}$ solution $(0.5 \mathrm{M}, 0.375 \mathrm{ml})$ and absorbance was determined at $450 \mathrm{~nm}$ using a Smart-Spec ${ }^{\text {TM}} 3000$ spectrophotometer (Bio-Rad). One unit (U) of proteolytic activity was defined as equivalent to an absorbance increase by 0.02 per h at $450 \mathrm{~nm}$.

Elastin Congo red assay. The elastolytic activity of the culture supernatants was determined using elastin Congo red (ICN, Biomedicals Inc.) as a substrate with a modified method described by Caballero et al. (2001). Elastin Congo red $(5 \mathrm{mg})$ in $0.49 \mathrm{ml}$ of $10 \mathrm{mM}$ Tris/ $\mathrm{HCl}$, pH 8.0 with or without EDTA $(10 \mathrm{mM})$ was mixed with $0.01 \mathrm{ml}$ of the culture supernatant. The reaction mixture $(0.5 \mathrm{ml})$ was incubated at $37^{\circ} \mathrm{C}$ for $24 \mathrm{~h}$, centrifuged at $10000 \times \mathrm{g}$ for $15 \mathrm{~min}$ and the absorbance was recorded at $490 \mathrm{~nm}$ using a Smart-Spec ${ }^{\text {TM }} 3000$ spectrophotometer.

Staphylolytic activity assay. Staphylolytic activity of the supernatants was tested with a procedure of Caballero et al. (2001). Staphylococcus aureus strain ATCC 25923 was cultured in $\mathrm{LB}$ overnight at $37^{\circ} \mathrm{C}$ and the bacteria were pelleted and resuspended in $0.25 \mathrm{ml}$ of $25 \mathrm{mM}$ of diethanolamine, $\mathrm{pH}$ 9.5. After heating at $100^{\circ} \mathrm{C}$ for 10 min, the heat-killed $S$. aureus cells were diluted to a final $\mathrm{OD}_{595}$ of 1.0 . The assay was carried out at $37^{\circ} \mathrm{C}$ by adding $0.01 \mathrm{ml}$ of the supernatant mixed with the diethanolamine buffer $(0.09 \mathrm{ml})$ to $0.4 \mathrm{ml}$ of the heat-killed cell suspension. Staphylolysis was determined by measuring the change in $\mathrm{OD}_{595}$ every $30 \mathrm{~min}$ for 90 min using a Smart-Spec ${ }^{\text {TM }} 3000$ spectrophotometer.

Protease IV assay. Protease IV activity of the culture supernatants was specifically measured using the chromogenic peptide Chromozym PL (tosyl-Gly-Pro-Lys- $p$ nitroanilide, Sigma) and a modified method described by O'Callaghan et al. (1996). The culture supernatants (0.01 $\mathrm{ml}$ ) were mixed with $40 \mu \mathrm{g}$ of Chromozym PL in a buffer $(0.49 \mathrm{ml})$ consisting of $50 \mathrm{mM}$ Tris/ $\mathrm{HCl}, \mathrm{pH} 8.0$, and $150 \mathrm{mM} \mathrm{NaCl}$, with or without $2 \mathrm{mM}$ TLCK (tosyl-Llysine chloromethylketone, Sigma). The reaction mixture $(0.5 \mathrm{ml})$ was incubated at $37^{\circ} \mathrm{C}$ for $30 \mathrm{~min}$. Release of $p$-nitroanilide due to cleavage at lysine was measured at $410 \mathrm{~nm}$ using a Smart-Spec ${ }^{\mathrm{TM}} 3000$ spectrophotometer.

Alkaline protease activity assay. The alkaline protease activity was tested using a modified method described by Howe \& Iglewski (1984). Samples containing $10 \mathrm{mg}$ of Hide powder azure (Sigma) dissolved in a buffer $(0.75 \mathrm{ml})$ consisting of $20 \mathrm{mM}$ Tris/ $\mathrm{HCl}, \mathrm{pH}$ 8.0 and $1 \mathrm{mM} \mathrm{CaCl}_{2}$ were mixed with $0.25 \mathrm{ml}$ of the culture supernatants. The reaction mixtures $(1 \mathrm{ml})$ were incubated at $37^{\circ} \mathrm{C}$ for $1 \mathrm{~h}$ with constant rotation. The undissolved substrate was removed by centrifugation at $4000 \times g$ for $5 \mathrm{~min}$. The absorbance of the reaction mixtures was then determined at $595 \mathrm{~nm}$. Protease activity was expressed in terms of protease units per milliliter $(\mathrm{U} / \mathrm{ml})$, where one unit is equivalent to an increase in $\mathrm{OD}_{595}$ of 1.0 per $\mathrm{h}$ at $37^{\circ} \mathrm{C}$.

Zymography analysis of protease profiles. Casein or gelatin zymography was conducted following the procedures described by Caballero et al. (2001). Samples of the culture supernatants $(30 \mu \mathrm{l})$ were electrophoresed under non-reducing conditions using a 10\% SDS-PAGE with $0.1 \%$ casein or gelatin, at $4^{\circ} \mathrm{C}$. The gels were then soaked twice in $2.5 \%$ Triton $\mathrm{X}-100$ for $15 \mathrm{~min}$ and incubated at $37^{\circ} \mathrm{C}$ for $24 \mathrm{~h}$ in either casein gel substrate buffer $(50 \mathrm{mM}$ Tris/HCl, pH 7.6, $100 \mathrm{mM} \mathrm{NaCl}$ ) or gelatin gel substrate buffer $(50 \mathrm{mM}$ Tris/ $\mathrm{HCl}, \mathrm{pH} 8.0$, $10 \mathrm{mM} \mathrm{CaCl}_{2} 1 \mu \mathrm{M} \mathrm{ZnCl}, 150 \mathrm{mM} \mathrm{NaCl}$ ). The gels were stained for $60 \mathrm{~min}$ in $0.2 \%$ amido black and then destained in $10 \%$ acetic acid.

DNA isolation and PCR amplification. Total genomic DNA was obtained from the three $P$. aeruginosa strains according to the method described by Pitcher et 
al. (1989) and its concentration was estimated by electrophoresis with a molecular mass DNA marker. PCR amplifications for both elastase B and alkaline protease genes were performed using 100 ng of DNA and REDTaq Ready Mix PCR Reaction Mix (Sigma) in a $50 \mu \mathrm{l}$ final volume. Each PCR mixture contained $1.5 \mathrm{U}$ of TaqI polymerase, $1.5 \mathrm{mM} \mathrm{MgCl}_{2}, 0.2 \mathrm{mM}$ dNTP mix, and $0.4 \mu \mathrm{M}$ of each primer. Primers lasBF2 (forward, 5'-CCAGCCCGCTGACCCACAAGCTGTA-3') and lasBR1 (reverse, 5'-CATTCCT'TCCTGGAGTGCYRGCCG-3') were used to amplify a 650-bp fragment of the las $B$ gene using the following temperature profile: initial denaturation at $94^{\circ} \mathrm{C}$ for $4 \mathrm{~min}, 25$ cycles of denaturation $\left(1 \mathrm{~min}\right.$ at $\left.94^{\circ} \mathrm{C}\right)$, annealing $\left(40 \mathrm{~s}\right.$ at $\left.54^{\circ} \mathrm{C}\right)$ and extension $\left(72^{\circ} \mathrm{C}\right.$ for $\left.60 \mathrm{~s}\right)$, and a final extension at $72^{\circ} \mathrm{C}$ for $4 \mathrm{~min}$. The amplification of a 1580-bp-long fragment for the alkaline protease gene aprA was carried out using the primer pair aprA-F (forward, 5'-CCTGATCKGGCCGATAACTGCAAT-3') and aprA-R (reverse, 5'-GGAAGACASCTATCAAT'TCGAACAG-3') and PCR conditions as above, with the exception of the annealing temperature $\left(46^{\circ} \mathrm{C}\right)$ and extension time $(2 \mathrm{~min})$. PCR products for both genes were separated by $1.5 \%$ agarose gel electrophoresis using Tris-borate buffer containing $90 \mathrm{mM}$ Tris base, $90 \mathrm{mM}$ boric acid $90 \mathrm{mM}$ and $2.5 \mathrm{mM}$ EDTA, pH 8.

Determination of lethal activity of $P$. aeruginosa culture supernatants. For in vivo experiments, the 7 th instar G. mellonella larvae $(n=10)$ were injected with different doses of the culture supernatants. LB broth or M9 medium were used for control injections. After the treatment, the larvae were kept at $28^{\circ} \mathrm{C}$ in the dark on sterile Petri dishes and were observed for the occurrence of death over a period of $48 \mathrm{~h}$. The number of insects dead and alive for each dose was used to calculate the $\mathrm{LD}_{50}$ of the tested supernatants according to the arithmetic method of Reed \& Muench (1938). The median lethal doses, $\mathrm{LD}_{50}$, were expressed for each bacterial strain as the ratio of total proteolytic activity units/larva (U/larva) producing death of $50 \%$ of larvae. The experiment was repeated five times.

Statistical analysis. The data are presented as means \pm standard deviation (S.D.) for at least three experiments. In order to compare two means, statistical analysis was performed by Student's $t$-test.

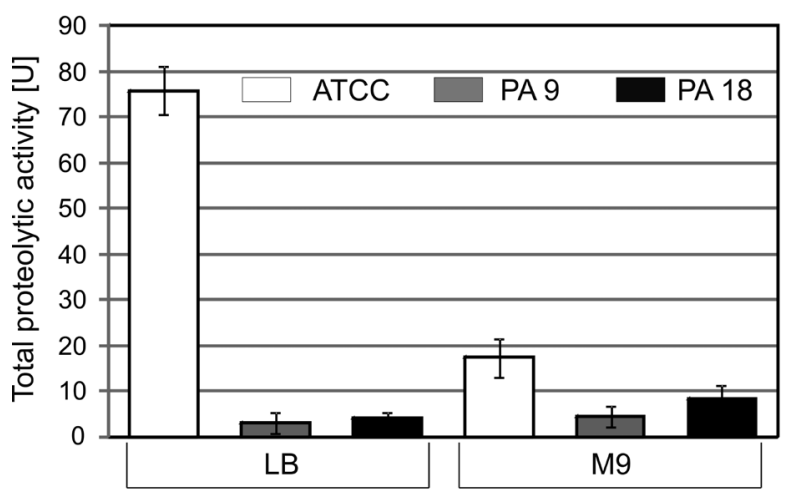

Figure 1. Comparison of total protease activity of culture supernatants of three $P$. aeruginosa strains.

Bacteria were cultured in LB or M9 medium for $24 \mathrm{~h}$ at $37^{\circ} \mathrm{C}$. Protease activity was measured with azocasein as a substrate (Materials and Methods). All values represent means \pm S.D. of at least ten independent experiments. ATCC, reference strain; PA9 and PA18, clinical isolates.

\section{RESULTS}

\section{Analysis of the total extracellular protease activity in $P$. aeruginosa culture supernatants}

Total proteinase activity in culture supernatants of three $P$. aeruginosa strains, ATCC 27853 - a reference strain, and two clinical isolates was determined. The activity was examined after culturing the bacteria in two different media: the minimal medium M9 and the rich $\mathrm{LB}$ broth after $24-\mathrm{h}$ incubation at $37^{\circ} \mathrm{C}$. The total proteolytic activity was evaluated with the azocasein assay.

Figure 1 presents the total protease activity produced by $P$. aeruginosa strains grown in the above-mentioned media. The highest proteolytic activity was observed for the ATCC strain growing in both LB and the minimal medium. However, the bacteria growing in LB exhibited a 5 -fold higher proteolytic activity than those growing in the M9 medium. Among the clinical strains, the highest activity was observed for the PA18 strain growing in the M9 medium, but it was lower by about $60 \%$ than the activity displayed by the ATCC strain in the same medium. In the other samples (PA9 LB, PA18 LB and PA9 M9) only a very low level of activity was observed (approximately $5 \%$ of the activity of ATCC LB). These results indicated that the production of extracellular proteases by $P$. aeruginosa was medium- and strain-dependent.

\section{Zymographic analysis of $P$. aeruginosa extracellular proteases}

The $P$. aeruginosa culture supernatants were examined by gelatin or casein zymography to differentiate the activities of protease IV, elastase B (LasB), elastase A (LasA) and alkaline protease. As can be seen in Fig. 2, the gelatin zymograms revealed different protease profiles depending on the strain and medium (LB or M9).

Gel electrophoresis (SDS/PAGE) under non-reducing conditions demonstrated three patterns of gelatinase activity in LB culture supernatants based on differences in electrophoretic mobility. One type, represented by the ATCC strain, was characterized by a combination of activities corresponding to molecular masses of $>200 \mathrm{kDa}$ and $160 \mathrm{kDa}$. Another type, represented by the PA9 strain was characterized by activities at $120 \mathrm{kDa}$, and the PA18 strain exhibited activity corresponding to an apparent molecular mass of $160 \mathrm{kDa}$ (Fig. 2). It has been reported that protease IV produces a proteolytic band of approximately $200 \mathrm{kDa}$ in gelatin and casein gels, where-
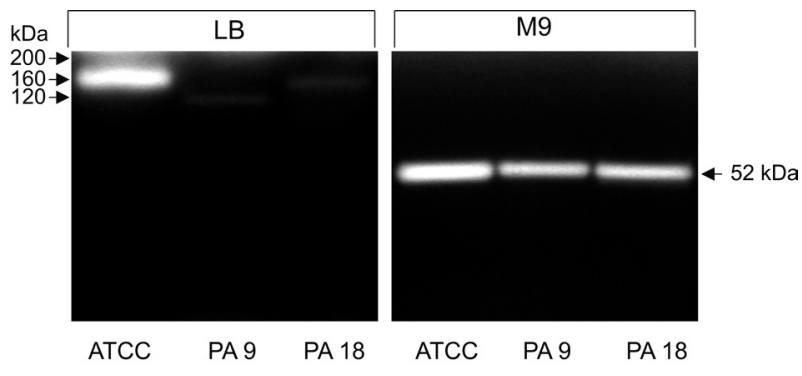

Figure 2. Gelatin zymogram analysis of culture supernatants of $P$. aeruginosa strains grown in LB and M9 medium.

Culture supernatants were electrophoresed under non-reducing conditions in a $10 \%$ polyacrylamide gel containing $0.1 \%$ gelatin. The gels were washed in Triton X-100, incubated at $37^{\circ} \mathrm{C}$ for $24 \mathrm{~h}$ in specific buffer and stained in amido black as described in Materials and methods. The zymograms shown are typical representatives of at least five independent experiments. ATCC, reference strain; PA9 and PA18, clinical isolates. 




Figure 3. Protease IV activity of culture supernatants of $P$. aeruginosa strains grown in LB and M9 medium.

Culture supernatants were incubated with Chromozym PL as a substrate (see Materials and Methods). Cleavage of the chromogenic peptide was measured by an increase in $\mathrm{OD}_{410}$. All values represent the mean \pm S.D. of three independent experiments. ATCC, reference strain; PA9 and PA18, clinical isolates.

as the band of $160 \mathrm{kDa}$ corresponds to elastase $\mathrm{B}$ and/ or elastase A activity (Caballero et al., 2001).

In contrast, for the three strains growing in the M9 medium, the zymogram revealed the presence of only one band with an apparent molecular mass of $52 \mathrm{kDa}$ (Fig. 2). It corresponded to the molecular mass of $P$. aeruginosa alkaline protease (Caballero et al. 2001). It was concluded that the strains grown in the minimal synthetic medium produced mainly alkaline protease (Fig. 2). Similar results were obtained when the supernatants were examined using casein zymography (data not shown).

\section{Specific enzyme assays}

We used specific activity assays to confirm the presence of particular proteases detected in the zymography gels.

The Chromozym PL degradation assay was performed specifically for protease IV. The results obtained clearly indicated that only the LB culture supernatant of strain ATCC exhibited a strong affinity to the chromogenic peptide Chromozym PL, a specific substrate for protease IV (Fig. 3). In the presence of $2 \mathrm{mM}$ TLCK, a selective inhibitor of serine proteases, its activity was completely inhibited (data not shown).



Figure 4. Staphylolytic (LasA) activity of culture supernatants of $P$. aeruginosa strains.

Culture supernatants in diethanolamine buffer were incubated with heat-killed S. aureus cell suspension (see Materials and Methods). Lysis of bacterial cells was determined by measuring the change in $\mathrm{OD}_{595}$. The data presented are typical representatives of five determinations. $C$, control, bacterial cells incubated alone.



Figure 5. Elastase activity of culture supernatants of $P$. aeruginosa strains.

Culture supernatants were incubated with elastin Congo red as described in Materials and Methods. After pelleting insoluble materials optical density of the solutions was determined at $490 \mathrm{~nm}$. The data presented are derived from five determinations and all values represent the mean \pm S.D.

To verify whether the $P$. aeruginosa strains studied secreted LasA, the staphylolytic activity of the supernatants was assayed using heat-killed $S$. aureus. The activity of elastase A was detected only in the LB supernatant of strain ATCC. It was evidenced by a rapid decrease of the optical density of the $S$. aureus suspension during the first 30 min of incubation in the presence of this culture supernatant. The optical density of the other samples remained indistinguishable from that of the control sample (Fig. 4).

On the other hand, the LasB activity identified using elastin Congo red was observed in the culture supernatants of all the $P$. aeruginosa strains studied (Fig. 5). Definitely, the highest activity was detected for the ATCC strain grown in the LB medium. The activity was nearly six-fold higher than that for this strain grown in the M9 medium. Significantly lower elastase B production was observed for the clinical strains in the LB medium, and only minimal cleavage of elastin Congo red was detected in the M9 supernatants of both clinical strains. In the presence of $10 \mathrm{mM}$ EDTA, an inhibitor of metalloproteinases, the activity of the enzyme was completely inhibited (data not shown).

The three $P$. aeruginosa culture supernatants obtained from the minimal medium were analysed by the hide powder azure degradation assay (Materials and Methods). The results indicated that all samples were able to hydrolyze hide powder azure, a substrate for $P$. aeruginosa alkaline protease (Fig. 6). The highest activity was determined in the supernatant of strain ATCC, while in the

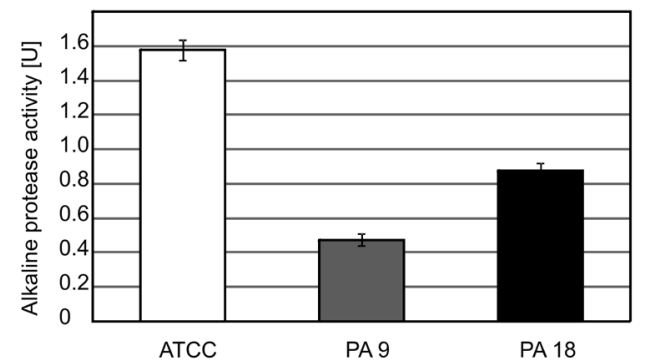

Figure 6. Alkaline protease activity of culture supernatants of $P$. aeruginosa strains grown in M9 medium.

Samples containing hide powder azure and culture supernatants were incubated for $1 \mathrm{~h}$ (Materials and Methods). Proteolytic activity was expressed in terms of protease units per milliliter $(\mathrm{U} / \mathrm{ml})$. The data presented are derived from three determinations and all values represent the mean \pm S.D. 
Table 1. Summary of proteolytic profiles of $P$. aeruginosa strains analyzed in this study.

\begin{tabular}{|c|c|c|c|c|c|}
\hline Medium & Strain & Las B activity* & Las A activity** & protease IV activity** & alkaline protease activity*** \\
\hline \multirow{3}{*}{ LB } & ATCC & 100 & + & + & - \\
\hline & PA9 & 8.7 & - & - & - \\
\hline & PA18 & 9.3 & - & - & - \\
\hline \multirow{3}{*}{ M9 } & ATCC & 16.8 & - & - & 100 \\
\hline & PA9 & 5.5 & - & - & 29.7 \\
\hline & PA18 & 4.8 & - & - & 55.7 \\
\hline
\end{tabular}

*Results are given as percentages of the reference strain ATCC LB activity $(100 \%)$ calculated on the basis of specific activity assay; ${ }^{* *}$ Activity of LasA and protease IV as detected in zymography gels as well as on the basis of specific activity assays; ***Results are given as percentages of the reference strain ATCC M9 activity (100\%) calculated on the basis of specific activity assay; (+) positive reaction (gelatinase activity); (-) negative reaction (no gelatinase activity).

case of clinical strains PA9 and PA18, the activity was lower by $70 \%$ and $45 \%$, respectively.

In general, there was a reasonably good correspondence between the results presented in the zymograms and the protease activity specific assays. Based on the above results we concluded that the ATCC strain produced three proteolytic enzymes in the LB medium: protease IV, elastase B and elastase A, but alkaline protease only in the M9 medium. The zymogram of the ATCC M9 culture supernatant did not show elastase B activity, although minimal cleavage of elastin Congo red was detected using the specific assay. In contrast, the clinical strains of $P$. aeruginosa produced elastase $B$ and alkaline protease when grown in the LB and M9 medium, respectively (Table 1).

\section{Identification of IasB and aprA genes in $P$. aeruginosa strains}

To confirm the production of LasB and alkaline protease, whose activity was detected by zymography and specific assays, by the clinical isolates, attempts were made to identify the corresponding genes in their genomes. In order to identify the las $B$ and apr $A$ genes in the genomes of the two $P$. aeruginosa clinical isolates (PA9 and PA18) and the reference strain ATCC 27853, in silico sequence analysis of these genes from several $P$. aeruginosa strains deposited at the GenBank database were performed. Then, sequence alignment for both las $B$ and aprA genes was performed, which facilitated choosing the most conserved sequence regions for primer design. The primer set used for lasB identification allowed amplifying a $0.65-\mathrm{kb}$ DNA fragment containing the 3'end of the gene. We obtained PCR products of the same length for the P. aeruginosa isolates PA9 and PA18, and the strain ATCC 27853 (Fig. 7). These results confirmed


Figure 7. PCR identification of lasB and aprA genes in genomes of $P$. aeruginosa strains.

Total genomic DNA of the strains studied was prepared and PCR amplifications were performed as described in Materials and Methods. PCR products for las $B$ and aprA genes were then separated by $1.5 \%$ agarose gel electrophoresis. $M$, DNA size marker. the presence of the las $B$ gene encoding elastase $\mathrm{B}$ in the genomes of all the three $P$. aeruginosa strains analyzed. Additionally, the presence of the second gene, aprA coding for the alkaline protease, was confirmed in the genomes of these strains. Using primers specific for aprA, we obtained 1.58-kb long amplicons encompassing the whole gene for alkaline protease for both the PA9 and PA18 isolates and the reference strain (Fig. 7).

\section{Toxicity of $P$. aeruginosa culture supernatants toward G. mellonella larvae}

To evaluate the contribution of elastase B and alkaline protease to the $P$. aeruginosa virulence, the toxicity of the culture supernatants toward 7th instar G. mellonella larvae was determined and $\mathrm{LD}_{50}$ values of the studied supernatants were calculated. The observed differences in the toxic effect of the culture supernatants were expressed for each bacterial strain as the ratio of the total proteolytic activity units/larva (U/larva).

The $P$. aeruginosa culture supernatants were toxic for $G$. mellonella larvae and an evident relationship was observed between the proteolytic activity of the supernatants and their $\mathrm{LD}_{50}$ values. There was no mortality in the control group. The culture supernatants of the ATCC strain exhibited a stronger toxicity to $G$. mellonella larvae than the corresponding culture supernatants of either clinical strain. It is noteworthy that the proteins secreted by $P$. aeruginosa strains into the minimal medium were much more toxic toward the caterpillars than those released into the LB broth. Median lethal doses, $\mathrm{LD}_{50}$ of the M9 culture supernatants were about 50-fold and 22-32-fold lower in comparison to the $\mathrm{LD}_{50}$ values calculated for the corresponding LB culture supernatants of the ATCC strain and the both clinical isolates, respectively. The $\mathrm{LD}_{50}$ values of the LB culture supernatants, containing mainly elastase B activity, were determined as $0.1,0.32$ and $0.45 \mathrm{U} /$ larva, respectively, for the ATCC strain, and the clinical strains 9 and 18. For the M9 culture supernatants exhibiting alkaline protease activity, the $\mathrm{LD}_{50}$ values were calculated as $0.002,0.01$ and $0.02 \mathrm{U} /$ larva for the ATCC strain, and the clinical isolates 9 and 18, respectively. The affected insects exhibited typical symptoms of $P$. aeruginosa infection. All larvae killed by the supernatant injections became black indicating strong activation of the prophenoloxidase system, which mediated melanization. Those results suggested that alkaline protease, besides elastase $\mathrm{B}$, con- 
tributed considerably to the virulence of the $P$. aeruginosa strains studied.

\section{DISCUSSION}

It has been reported that the $P$. aeruginosa entomopathogenic strain used in this study as a reference strain can produce four extracellular proteases, namely protease IV, elastase A, elastase B and alkaline protease (Morihara et al., 1965; Peters \& Galloway, 1990; Baumann et al., 1993; Engel et al., 1998), and these findings have been confirmed in our investigations. However, the gelatin zymography analysis revealed the presence of different protease profiles depending on the $P$. aeruginosa strain as well as on the medium used for bacterial culture.

The proteolytic band with a molecular mass above $200 \mathrm{kDa}$, detected by us in zymography, corresponded to protease IV activity. This is consistent with the results presented by Caballero et al. (2001), who reported that the enzyme aggregated under non-reducing conditions into a high-molecular-mass-complex $(>200$ $\mathrm{kDa}$ ). This serine proteinase was produced by the entomopathogenic strain ATCC in the LB medium only. Likewise protease IV, the activity of elastase A was detected in our studies only in the LB culture supernatant of the ATCC strain. In contrast, all three $P$. aeruginosa strains exhibited LasB activity. Elastase B produced by the ATCC strain in the LB medium migrated as a protein band of approximately $160 \mathrm{kDa}$, while the LB supernatants of the clinical isolates generated zymography bands of different molecular masses, i.e. $160 \mathrm{kDa}$ (PA18) or $120 \mathrm{kDa}$ (PA9). Other authors reported that elastase B migrated in gelatin zymography under nonreducing conditions as bands corresponding to apparent molecular masses of 116 or $163 \mathrm{kDa}$ (Engel et al., 1997; Stepińska et al., 2010). Furthermore, the apparent sizes of elastase B in polyacrylamide gels were dependent on the concentration of gelatin and polyacrylamide in the gels (Hummel et al., 1995). As demonstrated by Caballero et al. (2001), the $160 \mathrm{kDa}$ bands in gels with casein represented the proteolytic activity of LasB, whereas in the gelatin gels that band represented the combined activity of LasA and LasB. It was also reported that elastase $\mathrm{B}$ aggregated into a complex of high molecular mass, approximately $160 \mathrm{kDa}$. The two elastase B bands of molecular masses $160 \mathrm{kDa}$ and 120 $\mathrm{kDa}$ detected by us could reflect aggregation of different monomer numbers or aggregate formation with other proteins. Lomholt et al. (2001) postulated that the two mobility variants of elastase B in gelatin gels could reflect different conformations of the mature proteins resulting from differences in the las $B$ gene sequence or the formation of sequence-dependent non-covalently linked oligomers.

The gelatinase activity of the $P$. aeruginosa M9 culture supernatants showed that all the strains studied produced alkaline protease selectively only under those conditions. That protease was not produced in the LB medium. This finding is in agreement with data of Cryz \& Iglewski (1980), who found that production of alkaline protease was strain-variable and medium-dependent. The molecular mass of alkaline protease was calculated as $48.4 \mathrm{kDa}$ on the basis of purified enzyme migration in SDS/PAGE however, the enzyme was reported to migrate under non-reducing conditions as a band corresponding to an apparent molecular mass of $53 \mathrm{kDa}$ in $7.5-10 \%$ gelatin gels, which is consistent with our results (Twining et al., 1993; Engel et al., 1997).
Although all three $P$. aeruginosa strains tested in this study produced elastase $\mathrm{B}$ and alkaline protease, the activity level of these extracellular proteinases differed significantly between the strains. The proteinases of the clinical strains exhibited considerably lower activity in comparison to the ATCC strain enzymes. The detected differences in the activity level could be due to point mutations in the relevant genes affecting the enzyme activity. A detailed analysis of complete las $B$ and apr $A$ gene sequences in the $P$. aeruginosa strains studied, currently under way in our laboratory, will provide data for amino acid sequence analysis of the proteinases which will allow solving this question.

In this study, we showed that the $P$. aeruginosa clinical strains produced only two proteinases, elastase B and alkaline protease, and their expression was dependent on the composition of the media. In addition, the proteinase profiles of both clinical strains differed from the proteinase pattern of the $P$. aeruginosa ATCC strain. The observed differences could result from diverse requirements for expression of proteolytic activities by the strains studied.

Numerous studies have shown that $P$. aeruginosa isolates differ in expression of two virulence factors, elastase B and alkaline proteinase (Jagger et al., 1983; Woods et al., 1986; Schmidtchen et al., 2001). An analysis of different $P$. aeruginosa clinical isolates performed by Rumbaugh et al. (1999) suggested that both the infection site as well as the duration of infection influenced the virulence of the bacteria by altering production of extracellular virulence factors. It was reported that, despite the fact that the las $A$ and las $B$ genes were present in all $145 P$. aeruginosa isolates examined, 17 isolates did not exhibit elastase A activity, whereas 4 isolates failed to express elastase B (Lomholt et al., 2001).

The possible mechanism responsible for altering the production of these $P$. aeruginosa virulence factors is different regulation of $l a s B$ and $\operatorname{apr} A$ expression. $P$. aerugino$s a$ is known to contain a complex network of regulatory genes that influence the production of different virulence factors in response to changing environmental stimuli (Rumbaugh et al., 1999). A number of environmental factors have been shown to influence the production of $P$. aeruginosa exoproducts, e.g., the production of exotoxin $A$, elastase B and alkaline protease is independently regulated by iron (Bjorn et al., 1979; Shigematsu et al., 2001).

The synthesis and subsequent secretion of elastase B is regulated by quorum sensing as it is part of the las and $r b l$ regulons in $P$. aeruginosa. The two AHL-dependent QS systems (las and $r b l$ systems) regulate overlapping sets of genes and play a central role in the pathogenicity of $P$. aeruginosa. The expression of numerous cellular and secreted virulence factors, including alkaline protease, LasA and LasB proteases, exotoxin A, pyocyanin and lectins is regulated by the las and $r b l$ systems. In addition to the AHL-dependent quorum sensing system, expression of the lasB gene is also under regulation by the AQdependent QS system (Williams \& Camara, 2009).

It was shown by Duan \& Surette (2007) that expression of both QS systems in terms of magnitude as well as timing was dependent on the growth conditions, influencing expression of the QS-regulated virulence factors. For example, expression of the aprA gene encoding alkaline protease in the M9 minimal medium and diluted LB medium started already at the exponential phase, whereas in the rich LB medium the expression started at the early stationary phase. It was also reported that the expression levels of both QS systems were addi- 
tionally influenced by iron deprivation and oxygen limitation (Duan \& Surette, 2007). Exotoxin A production is regulated by the level of iron in the growth medium, the incubation temperature, and the presence of certain nutrients within the growth medium (Frank \& Iglewski, 1988).

In the genomes of the two clinical isolates as well as the reference strain of $P$. aeruginosa used in our study, genes las $B$ and aprA encoding elastase $\mathrm{B}$ and alkaline protease, respectively, were identified. The expression of those genes, coding for two important $P$. aeruginosa virulence factors, was dependent on the growth conditions in all the strains studied. Elastase B activity and alkaline protease activity were only detected in the rich LB medium and the minimal M9 medium, respectively. This essential difference could result from induction of the stringent response in the bacteria grown in the minimal medium. The stringent response occurs in reaction to starvation for a variety of nutrients, e.g. amino acids and fatty acids, and enables a broad-scale adaptation of the bacteria to stressful conditions (Jain et al., 2006). The role of the stringent response in the regulation of expression of virulence factors in $P$. aeruginosa has been demonstrated using a relA mutant unable to produce RelA, one of the enzymes responsible for the synthesis of the alarmone (p)ppGpp In the relA mutant a decrease in elastase and an increase in pyocyanin production were reported (Erickson et al., 2004). Moreover, a relA spoT $P$. aeruginosa double mutant, unable to produce both enzymes involved in (p)ppGpp synthesis, RelA and SpoT, was avirulent. The synthesis of virulence factors, such as elastase, pyocyanin, and siderophores was impaired in this double mutant (Vogt et al., 2011). In addition, relA mutants exhibited reduced virulence, while relA spoT double mutants were avirulent in Drosophila melanogaster feeding assay (Erickson et al., 2004; Vogt et al., 2011).

The fact that all the strains examined in this study contain the genes for elastase B and alkaline protease suggests that these enzymes are conserved and could confirm their role as important $P$. aeruginosa virulence factors. A great contribution of these extracellular proteinases to the virulence of the entomopathogenic as well as both clinical $P$. aerugionsa strains tested in this study was confirmed using a well established insect model organism, G. mellonella. Interestingly, the culture supernatants containing alkaline protease were considerably more toxic towards insect larvae in comparison to those containing mainly elastase $\mathrm{B}$, pointing to the importance of alkaline protease in overcoming mechanisms of immune response. However, in a discussion on the toxicity of the supernatants toward caterpillars, the role of other $P$. aeruginosa virulence factors, not tested in this study but most probably released into the culture medium along with the proteinases, should also be taken into consideration. As revealed in our previous paper, the LB and M9 culture supernatants of both clinical strains, despite containing elastase $\mathrm{B}$ and alkaline protease activity, respectively, hardly degraded G. mellonella hemolymph proteins and peptides in vitro. In contrast, after incubation in the presence of the ATCC strain culture supernatants, a strong proteolytic degradation of the larvae hemolymph polypeptides was detected (Andrejko et al., in press). Those results together with the toxicity study presented in this paper indicate that mainly extracellular proteinases could be involved in the toxicity of the ATCC strain supernatants toward G. mellonella, while for the toxicity of the clinical strains'supernatants most probably additional secreted virulence factors are responsible. For example, Miyata et al. (2003) have demonstrated a significant role of $P$. aeruginosa ADP-ribosyltransferase (ExoT) and phospholipase (ExoU) in killing of G. mellonella larvae.

Expression of virulence factors in $P$. aeruginosa is under comprehensive regulation and expression in vitro does not necessarily reflect the expression during infection. Certain strains may require additional signals or interactions that may not be present in vitro for expression of these genes. Since laboratory analyses of bacterial isolates need not fully reflect the true in vivo conditions, future studies should also include determinations of virulence factors in situ. The extracellular proteinases of $P$. aeruginosa strains used in this study are under further investigation in our laboratory using an insect model organism, G. mellonella.

\section{Acknowledgements}

The authors wish to thank Prof. E.A. Trafny (Department of Microbiology and Epidemiology, Military Institute of Hygiene and Epidemiology in Warsaw, Poland) for providing the clinical isolates of $P$. aeruginosa, and Prof. T. Jakubowicz for her advice concerning the studies performed and the present paper.

The work was financially supported by grant N N303 580239 from the Ministry of Science and Higher Education (Poland).

\section{REFERENCES}

Andrejko M, Zdybicka-Barabas A, Wawrzoszek M, Cytryńska M (2012) Diverse susceptibility of factors of Galleria mellonella humoral immune response to the exoproteinase activity of entomopathogenic and clinical strains of Pseudomonas aeruginosa. Zool Sci (in press).

Aperis G, Fuchs BB, Anderson CA, Warner JE, Calderwood SB, Mylonakis E (2007) Galleria mellonella as a model host to study infection by the Francisella tularensis live vaccine strain. Microb Infect 9: 729-734.

Baumann U, Wu S, Flaherty KM, McKay DB (1993) Three-dimensional structure of the alkaline protease of Pseudomonas aeruginosa: a two-domain protein with a calcium binding parallel beta roll motif. EMBO J 12: 3357-3364

Bjorn MJ, Sokol PA, Iglewski BH (1979) Influence of iron on yields of extracellular products in Psendomonas aeruginosa cultures. $J$ Bacteriol 138: 193-200.

Buret A, Cripps AW (1993) The immunoevasive activities of Pseudomonas aeruginosa: relevance for cystic fibrosis. Am Rev Respir Dis 148: 793-805.

Caballero AR, Moreau JM, Engel LS, Marquart ME, Hill JM, O’Callaghan RJ (2001) Pseudomonas aeruginosa protease IV enzyme assays and comparison to other Pseudomonas proteases. Anal Biochem 290: 330-337.

Cryz SJ, Iglewski BH (1980) Production of alkaline protease by Pseudomonas aeruginosa. I Clin Microbiol 12: 131-133.

Dart JK, Seal D (1988) Pathogenesis and therapy of Pseudomonas aeruginosa keratitis. Eye 2: 46-55.

Duan K, Surette MG (2007) Environmental regulation of Pseudomonas aeruginosa PAO1 Las and Rhl quorum-sensing systems. J Bacteriol 189: $4827-4836$.

Dulon S, Leduc D, Cottrell GS, D'Alayer J, Hansen KK, Bunnett NW, Hollenberg MD, Pidard D, Chignard M (2005) Pseudomonas aeruginosa elastase disables proteinase-activated receptor 2 in respiratory epithelial cells. Am J Respir Cell Mol Biol 32: 411-419.

Dunphy GB, Morton DB, Kropinski A, Chadwick JM (1986) Pathogenicity of lipopolysaccharide mutants of Pseudomonas aeruginosa for larvae of Galleria mellonella: bacterial properties associated with virulence. J Invertebr Pathol 47: 48-55.

Engel LS, Hill JM, Caballero AR, Green LC, O'Callaghan RJ (1998) Protease IV, a unique extracellular protease and virulence factor from Pseudomonas aeruginosa. J Biol Chem 273: 16792-16797.

Engel LS, Hobden JA, Moreau JM, Callegan MC, Hill JM, O’Callaghan RJ (1997) Pseudomonas deficient in protease IV has significantly reduced corneal virulence. Invest Ophthalmol Vis Sci 38: 1535-1542.

Erickson DL, Lines JL, Pesci EC, Venturi V, Storey DG (2004) Pseudomonas aeruginosa relA contributes to virulence in Drosophila melanogaster. Infect Immun 72: 5638-5645.

Frank DW, Iglewski BH (1988) Kinetics of toxA and reg $A$ mRNA accumulation in Pseudomonas aeruginosa. I Bacteriol 170: 4477-4483.

Garcia-Lara J, Needham A, Foster S (2005) Invertebrates as animal models for Staphylococcus aureus pathogenesis: a window into hostpathogen interaction. FEMS Immunol Med Microbiol 43: 311-323. 
Harding CR, Schroeder GN, Reynolds S, Kosta A, Collins JW, Mousnier A, Frankel G (2012) Legionella pneumophila pathogenesis in the Galleria mellonella infection model. Infect Immun 80: 2780-2790.

Heck LW, Morihara K, Abrahamson DR (1986) Degradation of soluble laminin and depletion of tissue-associated basement membrane laminin by Pseudomonas aeruginosa elastase and alkaline protease. Infect Immun 54: 149-153.

Hoge R, Pelzer A, Rosenau F, Wilhelm S (2010) Weapons of a pathogen: proteases and their role in virulence of Pseudomonas aeruginosa. In Current Research, Technology and Education Topics in Applied Microbiology and Microbial Biotechnology, number 2. Mendez-Vilas A, ed, pp 383-395. Microbiology book series, Formatex Research Center.

Hong YQ, Ghebrehiwet B (1992) Effect of Pseudomonas aeruginosa elastase and alkaline protease on serum complement and isolated components C1q and C3. Clin Immunol Immunopathol 62: 133-138.

Horvat RT, Parmely MJ (1988) Pseudomonas aeruginosa alkaline protease degrades human gamma interferon and inhibits its bioactivity. Infect Immun 56: 2925-2932.

Howe TR, Iglewski BH (1984) Isolation and characterization of alkaline protease-deficient mutant of Pseudomonas aeruginosa in vitro and in a mouse eve model. Infect Immun 43: 1058-1063.

Hummel KM, Penheiter AR, Gathman AC, Lilly WW (1995) Anomalous estimation of protease molecular weights using gelatine-containing SDS-PAGE. Anal Biochem 233: 140-142.

Hung C-Y, Seshan K, Yu JJ, Schaller R, Xue J, Basrur V, Gardner M, Cole G (2005) A metalloproteinase of Coccidioides posadasii contributes to evasion of host detection. Infect Immun 73: 6689-6703.

Jacquot J, Tournier JM, Puchelle E (1985) In vitro evidence that human airway lysozyme is cleaved and inactivated by Pseudomonas aeruginosa elastase and not by human leukocyte elastase. Infect Immun 47: 555-560.

Jagger KS, Bahner R, Warren RLJ (1983) Protease phenotypes of Pseudomonas aeruginosa isolated from patients with cystic fibrosis. Clin $\mathrm{Mi}$ crobiol 17: 55-59.

Jain V, Kumar M, Chatterji D (2006) ppGpp: stringent response and survival. J Microbiol 44: 1-10.

Jander G, Rahme LG, Ausubel FM (2000) Positive correlation between virulence of Pseudomonas aeruginosa mutants in mice and insects. J Bacteriol 182: 3843-3845.

Jarosz J (1995) Interaction of Pseudomonas aeruginosa proteinase with the inducible non-self response system of insects. Cytobios 83: 71-84.

Jarvis WR, Martone WJ (1992) Predominant pathogens in hospital infections. I Antimicrob Chemother 29: 19-24.

Jin F, Matsushita O, Katayama S-I, Jin S, Matsushita C, Minami J, Okabe A (1996) Purification, characterization, and primary structure of Clostridium perfringens lambda-toxin, a thermolysin-like metalloprotease. Infect Immun 64: 230-237.

Kessler E, Israel M, Landshman N, Chechick A, Blumberg S (1982) In vitro inhibition of Pseudomonas aeruginosa elastase by metal-chelating peptide derivatives. Infect Immun 38: 716-723.

Kessler E, Safrin M, Abrams WR, Rosenbloom J, Ohman DE (1997) Inhibitors and specificity of Pseudomonas aeruginosa LasA. J Biol Chem 272: 9884-9889.

Kessler E, Safrin M, Olson JC, Ohman DE (1993) Secreted LasA of Pseudomonas aeruginosa is a staphylolytic protease. J Biol Chem 268: 7503-7508

Lomholt JA, Poulsen K, Kilian M (2001) Epidemic population structure of Pseudomonas aeruginosa: evidence for a clone that is pathogenic to the eye and that has a distinct combination of virulence factors. Infect Immun 69: 6284-6295.

Maeda H, Morihara K (1995) Serralysin and related bacterial proteinases. Methods Enzymol 248: 395-413.

Maeda H, Yamamoto T (1996) Pathogenic mechanisms induced by microbial proteases in microbial infections. Biol Chem Hoppe-Seyler 377: 217-226.

Mariencheck WI, Alcorn JF, Palmer SM, Wright JR (2003) Pseudomonas aeruginosa elastase degrades surfactant proteins A and D. Am J Cell Mol Biol 38: 528-537.

Matthews BW (1988) Structural basis of the action of thermolysin and related zinc peptidases. Acc Chem Res 21: 333-340.

Miyata S, Casey M, Frank DW, Ausubel FM, Drenkard E (2003) Use of the Galleria mellonella caterpillar as a model host to study the role of the type III secretion system in Pseudomonas aeruginosa pathogenesis. Infect Immun 71: 2404-2413.

Miyoshi S, Shinoda S (2000) Microbial metalloproteases and pathogenesis. Microb Infect 2: 91-98.

Miyoshi S-I, Sonoda Y, Wakiyama H, Rahman M, Tomochika K, Shinoda S, Yamamoto S, Tobe K (2002) An exocellular thermolysinlike metalloproteinase produced by Vibrio fluvialis: purification, characterization, and gene cloning. Microb Pathol 33: 127-134.

Morihara K, Tsuzuki H, Oda K (1979) Protease and elastase of Pseudomonas aeruginosa: inactivation of human plasma $\alpha_{1}$-proteinase inhibitor. Infect Immun 24: 188-193.
Morihara K. Tsuzuki H, Oka T (1973) On the specificity of Pseudomonas aeruginosa alkaline proteinase with synthetic peptides. Biochim Biophys Acta 309: 414-429.

Morihara K, Tsuzuki H, Oka T, Inoue H, Ebata M (1965) Psendomonas aeruginosa elastase isolation, crystallization, and preliminary characterization. J Biol Chem 240: 3295-3304.

Mukherjee K, Altincicek B, Hain T, Domann E, Vilcinskas A, Chakraborty T (2010) Galleria mellonella as a model system for studying Listeria pathogenesis. Appl Environ Microbiol 76: 310-317.

O'Callaghan RJ, Engel LS, Hobden JA, Callegan MC, Green LC, Hill JM (1996) The role of an uncharacterized exoprotein, protease IV, in corneal virulence. Invest Ophthalmol Vis Sci 37: 1-10

Okuda K, Morihara K, Atsumi Y, Takeuchi H, Kawamoto S, Kawasaki H, Suzuki K, Fukushima J (1990) Complete nucleotide sequence of the structural gene for alkaline proteinase from Pseudomonas aeruginosa IFO 3455. Infect Immun 58: 4083-4088.

Park PW, Pier GB, Preston MJ, Goldberger O, Fitzgerald ML, Bernfield M (2000) Syndecan-1 shedding is enhanced by LasA, a secreted virulence factor of Pseudomonas aeruginosa. J Biol Chem 275: 3057-3064.

Park S, Kim KM, Lee JH, Seo SJ, Lee LH (2007) Extracellular gelatinase of Enterococcus faecalis destroys a defense system in insect hemolymph and human serum. Infect Immun 75: 1861-1869.

Parmely M, Gale A, Clabaugh M, Horvat R, Zhou WW (1990) Proteolytic inactivation of cytokines by Pseudomonas aeruginosa. Infect Immun 58: 3009-3014.

Peters JE, Galloway DR (1990) Purification and characterization of an active fragment of the LasA protein from Pseudomonas aeruginosa: enhancement of elastase activity. J Bacteriol 172: 2236-2240.

Pitcher DG, Saunders NA, Owen RJ (1989) Rapid extraction of bacterial genomic DNA with guanidium thiocyanate. Lett Appl Microbiol 8: 151-156.

Preston MJ, Seed PC, Toder DS, Iglewski HB, Ohman DE, Gustin JK, Goldberg JB, Pier GB (1997) Contribution of proteases and LasR to the virulence of Pseudomonas aeruginosa during corneal infections. Infect Immun 65: 3086-3090.

Pruitt BA Jr, McManus AT, Kim SH, Goodwin CW (1998) Burn wound infections: current status. World J Surg 22: 135-145.

Reed LJ, Muench H (1938) A simple method of estimating fifty percent endpoints. Am J Hyg 27: 493-497.

Rumbaugh KP, Griswold JA, Hamood AN (1999) Pseudomonas aeruginosa strains obtained from patients with tracheal, urinary tract and wound infection: variations in virulence factors and virulence genes. J Hosp Infect 43: 211-218.

Schmidtchen A, Wolff H, Hansson C (2001) Differential proteinase expression by Pseudomonas aeruginosa derived from chronic leg ulcers. Acta Derm Venereol 81: 406-409.

Schultz DR, Miller KD (1974) Elastase of Pseudomonas aeruginosa: inactivation of complement components and complement-derived chemotactic and phagocytic factors. Infect Immun 10: 128-135.

Seed KD, Dennis JJ (2008) Development of Galleria mellonella as an alternative infection model for the Burkholderia cepacia complex. Infect Immun 76: 1267-1275.

Shigematsu T, Fukushima J, Oyama M, Tsuda M, Kawamoto S, Okuda K (2001) Iron-mediated regulation of alkaline proteinase production in Pseudomonas aeruginosa. Microbiol Immunol 45: 579-590.

Stępińska MA, Ołdak E, Trafny EA (2010) Proteolytic activity of Pseudomonas aeruginosa isolates with TTSS-mediated cytotoxicity and invasiveness to host cells. Curr Microbiol 60: 360-364.

Thayer MM, Flaherty KM, McKay B (1991) Three-dimensional structure of the elastase of Psendomonas aeruginosa at $1.5-\AA$ resolution. $J$ Biol Chem 266: 2864-2871.

Toder DS, Gambello MJ, Iglewski BH (1991) Psendomonas aeruginosa LasA: a second elastase under the transcriptional control of lasR. Mol Microbiol 5: 2003-2010.

Twining SS, Kirschner SE, Mahnke LA, Frank DW (1993) Effects of Pseudomonas aeruginosa elastase, alkaline protease and exotoxin A on corneal proteases and proteins. Invest Ophthalmol Visual Sci 34: 2699-2712.

Vogt SL, Green C, Stevens KM, Day B, Erickson DL, Woods DE, Storey DG (2011) The stringent response is essential for Pseudomonas aeruginosa virulence in the rat lung agar bead and Drosophila melanogaster feeding models of infection. Infect Immun 79: 4094-4104.

Williams P, Camara M (2009) Quorum sensing and environmental adaptation in Pseudomonas aeruginosa: a tale of regulatory networks and multifunctional signal molecules. Curr Opin Microbiol 12: 182-191.

Woods DE, Schaffer MS, Rabin HR, Campbell GD, Sokol PA (1986) Phenotypic comparison of Pseudomonas aeruginosa strains isolated from a variety of clinical sites. J Clin Microbiol 24: 260-264. 